\title{
Über den Kieselsäuregehalt der Warthonschen Sulze menschlicher Nabelstränge.
}

\author{
Von
}

Dr. Franz Frauenberger, Assistent.

(Aus dem Universitätslaboratorium für medizinische Chemie Wien.)

(Der Redaktion zugegangen am 18. Juli 1908.)

In seinen Abhandlungen „Über den Kieselsäuregehalt menschlicher und tierischer Gewebe“" 1 ) und „Weitere Mitteilungen über den Kieselsäuregehalt tierischer und menschlicher Gewebe, insbesondere der Warthonschen Sulze“"2) kommt Schulz zu dem Ergebnis, daß der Kieselsäuregehalt von dem Gehalte der einzelnen Organe an Bindegewebe abhängig ist; bei gleichem Gewebe ist er in der Jugend größer als im Alter und erreicht seinen höchsten Wert im embryonalen Bindegewebe, der Warthonschen Sulze.

Für diese hat er im Mittel einen Gehalt von 0,5985 \% Kieselsäureanhydrid, bezogen auf reine Asche, gefunden.

$\mathrm{Da}$ im obengenannten Laboratorium bei zahlreichen, im Laufe von drei Dezennien vorgenommenen Untersuchungen verschiedener menschlicher Organe auf ihre mineralischen Bestandteile (mit Ausnahme der Lunge) niemals ein so hoher Kieselsäuregehalt beobachtet worden war, so war die Anregung gegeben, die Untersuchungen von Schulz zu wiederholen; es war dies um so leichter möglich, als Herr Hofrat Professor Dr. R. Ghroback, Vorstand der hiesigen I. geburtshilflichgynäkologischen Klinik, bereitwillig das dazu erforderliche Material zur Verfügung stellte.

Die Untersuchungen wurden in folgender Weise ausgeführt:

1) Archiv für die gesamte Physiologie, Bd. LXXXIV, S. 67.

2) Archiv für die gesamte Physiologie, Bd. LXXXIX, S. 112.

Hoppe-Seyler's Zeitschrift f. physiol. Chemie. LVII. 
Die Nabelstränge im Gewichte von 508,2 g wurden so, wie ich sie von der Klinik erhielt, ohne weitere Vorbereitung in 5-6 cm lange Stücke geschnitten und diese in einer geräumigen Platinschale auf dem Wasserbade getrocknet, wobei, wie bei allen späteren Operationen, der Zutritt von Staub aus der Luft möglichst abgehalten war.

Das trockene Material wurde sodann auf einem Gasofen bei vorsichtig und allmählich gesteigerter Hitze, wobei es nicht bis zur sichtbaren Rotglut kam, verkohlt, die erkaltete kohlige Masse mit heißem Wasser ausgelaugt, die entstandene Lösung durch ein kleines aschefreies Filter filtriert, dieses mit destilliertem Wasser gut nachgewaschen, Filtrat und Waschwasser in einer tarierten Platinschale zur Trockene verdampft, der Rückstand bei $110^{\circ} \mathrm{C}$. bis zum konstanten Gewichte getrocknet und gewogen. Sein Gewicht betrug 4,2062 g.

Das kleine Filter samt der darin befindlichen Kohle wurde in die Platinschale, welche zur Verkohlung gedient hatte, zurückgebracht, die Kohle durch weiteres Erhitzen vollständig verbrannt, die zurückgebliebene Asche gewogen, das Gewicht betrug $0,4111 \mathrm{~g}$. Demnach hatten die Nabelstränge im Gewicht von 508,2 $\mathrm{g}$ insgesamt $4,6173 \mathrm{~g}$ Asche geliefert.

Diese gesamte Asche wurde nun mit Salzsäure bis zur stark sauren Reaktion versetzt und in der Platinschale auf dem Wasserbade zur Trockene verdampft, der Trockenrückstand noch weiter etwa 2-3 Stunden auf dem Wasserbade zur Abscheidung der Kieselsäure erwärmt, dann wurde der so getrocknete Rückstand mit Salzsäure befeuchtet, mit Wasser versetzt, bis die Salzmasse gelöst war, wobei sich nur wenige Flocken von Kieselsäure abschieden. Nach mehrstündigem Stehen wurde die Kieselsäure quantitativ auf ein kleines aschefreies Filter gebracht und die auf dem Filter befindliche Kieselsäure mit Wasssr gut gewaschen; die von der Kieselsäure abfiltrierte Flüssigkeit wurde mit Ammoniak gefällt, der Niederschlag auf ein aschefreies Filterchen gebracht und gut gewaschen; hierauf beide Filter noch feucht und gut zusammengefaltet in einen gewogenen Platintiegel gebracht und bei sehr vorsichtig gesteigertem Erhitzen, 
um Verstauben von Kieselsäure zu verhindern, getrocknet, verkohlt, endlich die Kohle verbrannt. Der zurückbleibende Glührückstand wurde gewogen, das Gewicht betrug 0,0032 g.

Nach dem Wägen wurde in den Tiegel ein Tröpfchen verdünnte Schwefelsäure und etwa $1 \mathrm{ccm}$ reiner, wässeriger Flußsäure gebracht, die Flüssigkeit auf dem Wasserbade abgedampft, um die Kieselsäure zu vertreiben, der geringe $\mathrm{Ab}$ dampfrückstand vorsichtig erhitzt und zuletzt bis zum konstanten Gewichte geglüht. Das Gewicht des durch Flußsäure nicht verflüchtigbaren Rückstandes betrug 0,0014 g.

Dieser wurde mit Wasser und einigen Tropfen Salzsäure gelöst, heiß mit Chlorbaryum gefällt, das ausgefällte Baryumsulfat lege artis behandelt, nach dem Glühen gewogen, sein Gewicht betrug 0,0006 g, entsprechend 0,0002 g Schwefelsäureanhydrid. Demnach wurden aus 508,2 $\mathrm{g}$ Nabelsträngen $0,0020 \mathrm{~g}$ Kieselsäureanhydrid abgeschieden, dies entspricht einem Prozentgehalt der Nabelstränge an Kieselsäure $=0,0004 \%$. Die Asche der Nabelstänge enthielt demnach 0,043\% Kieselsäureanhydrid.

Bei Untersuchung der Warthonschen Sulze wurde genau nach den Angaben von Schulz vorgegangen: Die Nabelstränge wurden mit destilliertem Wasser abgespült, in 5-6 cm lange Stücke geschnitten, diese in einer Platinschale so lange mit destilliertem Wasser gewaschen, bis kein Blutfarbstoff mehr wegging, dann der Länge nach gespalten. Die Gefäße wurden nun herauspräpariert und die einzelnen Stücke abermals mit destilliertem Wasser gewaschen und in einer Platinschale auf dem Wasserbade getrocknet. Der Trockenrückstand wurde, wie oben beschrieben, weiterbehandelt.

Die Bestimmung des Trockenrückstandes und der Asche geschah in eigenen kleinen Portionen und es lieferten:

I. 2,4364 $\mathrm{g}$ Warthonscher Sulze $0,1644 \mathrm{~g}$ Trockenrückstand und $0,0198 \mathrm{~g}$ Asche, entsprechend $0,81 \%$ der Sulze, 12,04 \% der Trockensubstanz. II. $2,3671 \mathrm{~g}$ Warthonscher Sulze $0,1505 \mathrm{~g}$ Trockenrückstand und $0,0170 \mathrm{~g}$ Asche, entsprechend 0,72\% der Sulze oder 11,29\% der Trockensubstanz.

Die Gesamtasche der Warthonschen Sulze betrug 3,5113 g, davon entfielen auf den im Wasser löslichen Anteil $2,9817 \mathrm{~g}$, 
auf den im Wasser unlöslichen Anteil 0,5296 g. Die Differenzen aus den Wägungen der. Glührückstände vor und nach der Behandlung mit Flußsäure und Schwefelsäure ergaben insgesamt $0,0010 \mathrm{~g}$; mithin fand sich in $3,5113 \mathrm{~g}$ Asche Warthonscher Sulze $0,0010 \mathrm{~g}$ Kieselsäureanhydrid entsprechend $0,0284 \%$ der Asche.

Um die eingeschlagene Methode auf ihre Verläßlichkeit zu prüfen, wurde einer dritten Portion von Nabelsträngen die ihnen nach den Angaben von Schulz beiläufig zukommende Menge reiner Kieselsäure $(0,0208 \mathrm{~g})$ zugesetzt; auch diese Untersuchung wurde wie die erste zu Ende geführt.

Die Gesamtasche betrug 4,5536 g. Die gefundene Menge Kieselsäureanhydrid betrug $0,0220 \mathrm{~g}$. Nach Abzug der zugesetzten Kieselsäure entfallen mithin auf 4,5328 g Asche 0,0012 g Kieselsäureanhydrid, entsprechend 0,027\% der Asche. Aus dem Ergebnis der Untersuchung geht hervor, daß der Kieselsäuregehalt der Warthonschen Sulze menschlicher Nabelstränge bedeutend geringer ist, als ihn Schulz gefunden hat. Die Untersuchung von Schulz ergab nämlich für die Asche der Warthonschen Sulze 0,5985 \%, meine Untersuchung ergab dagegen nur 0,0284\% Kieselsäureanhydrid. 